\title{
PERCEPÇÃO DOS TRABALHADORES DE SAÚDE QUANTO ÀS MUDANÇAS OCORRIDAS NOS SERVIÇOS A PARTIR DA IMPLANTAÇÃO DO SUS: A PRÁtiCA NA TEORIA
}

Cláudia Maria Bógus*

RESUMO:A partir de alguns depoimentos colhidos entre servidores públicos de um serviço municipalizado de saúde que mostram como eles têm percebido (ou não) as mudanças ocorridas no sistema de saúde. foi possivel confirmar a hipótese de que existem dificuldades na concretização das politicas públicas e também desintegração entre os niveis central, intermediário e periférico da rede de senviços de saúde.

Com o intuito de se encaminhar para mudanças na prática cotidiana dos servidores, destaca-se a importante contribuição que a àrea de treinamento $e$ desenvolvimento poderia ter, através de propostas que privilegiassem o profissional de saúde como trabalhador coletivo e como agente de mudança dos serviços públicos de saúde.

O objetivo deste breve ensaio é procurar mostrar, aproveitando alguns depoimentos colhidos no periodo compreendido entre 1989 e 1991, junto a servidores públicos de um serviço municipalizado de saúde (municipio de pequeno porte na região da Grande São Paulo), como eles têm percebido (ou não) as mudanças ocorridas no sistema de saúde, a partir da implantação de alguns dos

\footnotetext{
"Educadora de Saude Publica da Secretaria Municipal de Saude: Distrito da Freguesia do O Aluna do Curso de Pós-Graduação da FSPNSP - Doutorado.
} 
principios defendidos pelo movimento da Reforma Sanitária, e institucionalizados pela Constituição Federal promulgada em 1988.

A partir disso será possivel reforçar a hipótese de que existern dificuldades na concretização das políticas públicas que, tradicionalmente, não se completam na sua passagem da elaboração às ações. Existe, na realidade. desintegração entre os niveis central, intermediário e periférico da rede de serviços.

A articulação entre os niveis macro e micro de análise é uma das questões mais significativas que marcam atualmente o estudo na área de Saude Coletiva.

Nesse sentido se colocam as análises referentes à área de recursos humanos, principalmente ao se tentar verificar, através dos mais variados estudos. a aplicabilidade de conceitos e modelos, buscando uma aproximação entre a teoria (marco explicativo central) e a prática (realidade dos serviços).

O estudo de realidades municipais, em análises conjunturais, com o intuito de conhecer como tem se dado a implantação da municipalização dos serviços de saúde, tem mostrado que os resultados encontrados podem ser diferentes dos previstos em vários aspectos como, por exemplo, o controle social, o modelo assistencial implantado, o comprometimento dos profissionais perante a clientela e a descentralização, hierarquização, integração dos serviços e a autonomia local.

No caso deste ensaio a análise a ser apresentada parte do micro contexto e da prática política, enquanto exercicio de responsabilidade pública. dos servidores públicos, apresentada através de seus depoimentos. 
É preciso, então, caracterizar este micro contexto do qual se partiu para realizar tal análise. De modo geral este serviço local funcionava de forma diferenciada de outros serviços similares. A própria possibilidade de realização de um trabalho junto aos recursos humanos que originou os depoimentos aqui apresentados é uma demonstração disto.

No caso dos recursos humanos existem grandes dificuldades para a implementação, nos serviços de saúde, das ações formuladas para a formação e capacitação de pessoal. O caminho de difusão das políticas do nível central e da academia para o nivel de execução é tortuoso, e por isso as idéias básicas se perdem ou se transformam, impedindo a concretização das mudanças.

Mesmo com esta situação geral, no nível local foi possível desenvolver um trabalho com os funcionários em que questōes referentes às expectativas quanto às ações desenvolvidas, o trabalho em equipe, e o modelo assistencial puderam ser colocadas e discutidas.

Nesse caminho é muito difícil a tarefa dos órgãos que têm que arcar com a busca de formas para a operacionalização das novas diretrizes. Eles se encontram num nivel intermediário: entre os órgãos centrais encarregados de formular diretrizes e os órgãos que prestam serviços e pressionam, segundo a lógica das necessidades mais imediatas.

O nivel intermediário é responsável pela incorporação das mudanças pretendidas em relação à forma e/ou conteúdo das atividades de formação e capacitação, ao mesmo tempo que se depara com a memória das experiências passadas, as pressões a nivel local, a insuficiência dos recursos disponiveis e a instabilidade temporal dos projetos efetivamente implantados. 
Em resumo, avaliações quanto à situação dos recursos humanos no processo de municipalização dão conta, além da ausência de diretrizes na área de treinamento e desenvolvimento que prejudicam o que se refere a mudanças de postura profissional, também da ausência de legislação e regulamentação que dêem sustentação à implantação do Sistema Único de Saúde.

As investigações nos niveis dos micro contextos têm detectado que a administração de recursos humanos é um problema crucial nos municípios imbricado com diversas outras áreas da administração local.

Sem cair num extremismo que atribui às propostas de intervenção sobre recursos humanos uma potencialidade de modificam sozinhas os serviços de saúde, é preciso reconhecer que a intervenção nessa área, ao estar articulada com uma discussão sobre o modelo assistencial, poderá contribuir muito com a qualidade dos serviços prestados.

A $1^{\text {a }}$ Conferência Estadual de Saúde de São Paulo (1991) destacou, quanto à política de recursos humanos, três aspectos que sintetizam o modo como se pode encarar os recursos humanos e, conseqüentemente, como deveriam ser abordados:

1. como principal riqueza e patrimônio do Sistema Único de Saúde: partindo do principio que os resultados do setor saúde, quantitativos ou qualitativos, dependem muito da relação entre cliente/comunidade e a equipe de saúde, é preciso pensar os gastos com o setor como investimentos de grande importância; 
2. como meio para a produção dos serviços de saúde: o investimento em recursos humanos é fundamental para alcançar bons resultados, como a melhoria dos niveis de saúde da comunidade atendida;

3. como agentes de mudança: ao serem sensibilizados pelos objetivos do Sistema Único de Saúde, os trabalhadores da área de saúde podem se constituir em importantes multiplicadores de idéias e agentes de mudança no serviço de saúde.

Partindo principalmente do terceiro aspecto apontado poderia se esperar que os próprios trabalhadores se constituissem como um todo e em todas as categorias, como sujeitos do processo de reorganização do sistema de saúde. Aí se incluiria a democratização das informações e das decisões nos serviços, a integração das equipes e a integralidade da assistência, a participação interna e outros.

Analisando especificamente os trabalhadores de saúde do serviço municipal estudado, com relação à democratização e circulação das informações dentro do mesmo serviço, as referências indicam que dificuldades na comunicação interna permaneceram após a implantação oficial das diretrizes do SUS:

- "a gente tem uma reunião por mês de equipe: é muito pouco. Como vai circular uma informação legal? Porque uma coisa é estar com uma pessoa, depois com a outra, separadamente. O que uma fica sabendo, a outra não fica."

Também não há integração entre as equipes e nem no trabalho realizado, que continuou fragmentado:

- "eu acho que a dificuldade entre as equipes existe sim". 
- "a gente não conhece o trabalho geral".

Por outro lado é importante refletir que são muito poucos os serviços em que reuniões mensais ocorrem proporcionando momentos de discussão conjunta entre os profissionais, inclusive com a perspectiva de busca de integração entre as equipes. É possivel pelo menos perceber que tal preocupação não faz parte da maior parte dos serviços.

A falta de um plano adequado de cargos, carreiras e vencimentos aparece, indiretamente, como um fator prejudicial à integração no trabalho, impedindo que esforços de capacitação dos recursos humanos sejam eficazes:

- "... saiu muita gente por causa do salário".

- "... Acho que no serviço tem essa coisa das equipes não serem constantes, há muitas mudanças, que prejudicam o relacionamento e o trabalho".

Com relação à finalidade da Unidade Básica de Saúde é possível perceber que a dicotomia entre o curativo e o preventivo que o SUS, nos seus pressupostos filosóficos, pretenderia eliminar, ainda está presente. Neste aspecto foi possivel identificar um avanço positivo; o surgimento da preocupação com os aspectos preventivos e a percepção de que isto não acontece o tempo todo:

- "... tratar de doentes".

- "... é saúde pública, prevenção, mas isso não acontece sempre".

- "serve também para orientar. Porque, parece que aqui estão aprendendo mais, porque aqui tem orientação dos médicos, das enfermeiras, 
orientação de gravidez, de aborto, de anticoncepcionais, preservativos, DIU, tem tudo nesse prédio".

Aparece na fala de alguns uma preocupação em atuar de uma forma diferente, através de um novo modelo assistencial. $O$ fato disso só ser citado por alguns, entretanto, mostra que nem todos têm tido acesso à informações sobre o que se tem discutido a respeito:

- "... mas prá gente quebrar essa barreira entre médico e paciente o que a gente tem que fazer é a proposta do médico de familia entendeu, ir até eles, atender toda a familia, conhecer os seus problemas, fazer uma visita na casa deles..."

- "... ser diferente dos médicos tradicionais sempre foi a minha meta desde que eu sou médico, não sei se eu tô ganhando com isso, mas me faz bem ser. (...) Eu converso diferente com as pessoas, com os pacientes, né? Com isso eu tô fazendo uma coisa que me satisfaz, tô provocando mudanças, o que é uma coisa boa."

Outro aspecto relacionado com o modelo assistencial é a percepção dos trabalhadores de saúde de como a população usuária estaria vendo a finalidade do serviço. Ao mesmo tempo que se reconhece o seu papel de servidor, criticam-se aqueles que não entendem o que devem vir fazer ali, como se a população tivesse obrigação de procurar os seus serviços de acordo com o que os profissionais de saúde já tivessem definido e discutido anteriormente. O problema é que, da mesma forma que nem todos os trabalhadores da área têm participado desta discussão, também a população não tem tido acesso nem às discussões e nem às informações: 
- "... Não só espera como ela (população) merece uma boa qualidade de assistência e nós como bons profissionais temos que dar essa boa qualidade, é obrigação nossa; nós estamos aqui para senvir essa comunidade. Se nós fizermos uma boa assistência não vamos estar fazendo mais do que a nossa obrigação."

- "... que é o objetivo aqui dessa unidade, é fazer um tratamento, né, bem mais especifico. De repente o pessoal chega aqui e tá com dor de cabeça, vem para passar, pegar um remédio e vai embora. Na semana que vem volta com dor de barriga. Não pensa que deveria fazer um tratamento... eu acho que o específico dessa unidade é fazer tratamento".

- "... só que os nossos pacientes aqui são mal acostumados, eles já entram na nossa sala: eu quero uma ambulância; eu quero que me aplique esse remédio, eles não chegam e pedem: por gentileza, pode me dar esse remédio?".

- "Eu acho que assim como nós, a maior parte dos brasileiros não vê assim a saúde pública como uma coisa necessária de saúde preventiva, acha que é só quando tá caindo aos pedaços que tem que aparecer no médico..."

Quanto à atitude diante da participação da população na gestão do serviço, outro principio fundamental do SUS, nota-se que, de modo geral, apresentam dúvidas quanto à possibilidade de um gerenciamento participativo e representativo que incluisse a população:

- "... a população só cobra a falta de médico, não entende o trabalho, né".

- "... eu já acho meio difícil esse pessoal (a população)". 
- "... Eu acho que tem pessoa que não pode, você vai conversar. fala o que ela tem que fazer, tenta fazer a pessoa entender e não adianta".

- "Eu acho que eles deveriam dar graças a Deus de ter um posto como esse, porque tem tanto lugar que não tem nem médico, mas não. eles querem ser atendidos na hora".

- "... no atendimento ao público, deveria ter uma pessoa prá lidar com o povo..."

- "... agora eu acho que é difícil a gente tá indo de noite na reunião e o pessoal fala um monte de coisas que não tem nada a ver (...) mas você vai ter que esperar essa coisa passar".

O mesmo ocorre quanto à participação dos próprios funcionários (participação interna), havendo dúvidas quanto à democratização interna:

- ".. os funcionários não falam porque têm medo, receio de uma perseguição, não sentem abertura".

- "... até se faz reunião para o pessoal participar. mas muitas vezes eles se recusam a ir, preferem ficar em atividade".

- "... então a gente vê nas pessoas que não sabem se colocar. têm medo porque não se tem essa vivência, nunca se deu essa abertura".

- ".. chega numa reunião eles (profissionais universitários) começam a falar umas coisas que tem a ver com eles e não a ver com todos, então não dá para entender (...) eles usam uma linguagem cientifica". 
- ".. então que raio de participação (interna) é essa? Ai fica fácil falar da coisa só para fora".

A relação interprofissional, que sempre aparece no plano da elaboração das políticas como fundamental para a implantação de mudanças, é apontada como terreno de conflitos latentes, e muitos se vêem como meros executores de tarefas pré-determinadas, bem ao contrário do que preconizaria qualquer discurso reformista:

- "Entrei para explicar o caso, ai ele falou assim: Não, a sua função é simplesmente fazer a ficha, você tá se preocupando à toa".

Além do conflito relacionado ao poder dentro da instituição:

- "Só o universitário que manda mesmo e resolve."

- ".. então fica nesse jogo de empurra-empurra, né? Acaba você fazendo uso de uma autoridade que as pessoas embutem também. quer dizer, as pessoas ficam naquela posição de tá esperando uma ordem tua, né? $E$ as pessoas acabam exercitando esta autoridade que é dada mesmo. dentro do próprio sistema. Eu, na medida do possivel, procuro dar uma controlada nisso ai. mas também tem um estímulo para você colocar sua autoridade prá fora. Aqui tem muito isso. As pessoas estão esperando que você exerça a autoridade de médico. é isso que estão pedindo o tempo inteiro".

- ".. algumas decisões eu acho que são técnicas mesmo. um grupo técnico tem que decidir, (...) até certo ponto é fantasia participarem de tudo. né? (...) porque tem especificidades que são médicas, tem especificidades que são de enfermagem e tem outras que são do Centro de Saúde como um todo". 
Juntando isso com questão da remuneração:

- "... como na gratificação, só para o pessoal universitário".

Os aspectos aqui levantados - poucos diante das várias possibilidades através das quais se procurou corroborar por meio de algumas frases pinçadas de uma pesquisa realizada num serviço local de saúde podem e devem ser aprofundados. Mas, de qualquer modo, já se pode comprovar a tese inicial de que existe uma distância entre a elaboração teórica e a prática vivenciada no campo da Saúde Coletiva, mesmo em serviços que se propuseram a tentar concretizar os pressupostos teóricos da Reforma Sanitária.

É no que se refere mudança da prática cotidiana dos servidores que a área de treinamento e desenvolvimento mais poderia contribuir, caminhando para propostas que privilegiassem a configuração do profissional da saúde como trabalhador coletivo, permitindo uma abordagem onde os profissionais de saúde se constituissem como agentes de mudança ao imprimirem um caráter para além do burocrático na sua atuação dentro dos senviços.

\section{BIBLIOGRAFIAS CONSULTADAS}

1. BÓGUS, C.M. A reforma sanitária e a educação continuada: a importância do investimento nos recursos humanos dos serviços locais de saúde. São Paulo, 1992. [Dissertação de Mestrado - Faculdade de Saúde Pública da USP].

2. COHN, A. As grandes questões de administração das politicas sociais (recursos humanos): de instituidos a instituintes. _Rev. Adm. públ., 22 (1): 25-31. 1988.

3. COHN, A. Conhecimento e prática em saúde coletiva: o desafio permanente. Saúde e Soc., 1(2):97-109, 1992. 
4. COHN, A. Trabalhar no serviço público de saúde: os agentes de saúde e a relação instituição/clientela. In: Saúde e cidadania. São Paulo, 1992. [Tese de Livre-Docência - Faculdade de Saúde Pública da USP].

5. CONFERÊNCIA ESTADUAL DE SAÚdE, 1a, São Paulo, 1991. Relatório síntese. São Paulo, Secretaria de Estado da Saúde, 1992.

6. MARSIGLIA, R.M.G. Unidades básicas de serviços de saúde. Disponibilidade tecnológica, processos de trabalho e recursos humanos. In: SPÍNOLA, A.W.P. et al. coord. Pesquisa social em saúde. São Paulo, Cortez, 1992. p. 213-24.

7. OLIVEIRA JUNIOR, M. Administração de recursos humanos: um obstáculo à municipalização dos serviços de saúde? Saúde Deb., (28): 41-5, 1990.

8. SANTANA, J.P. Formulação de políticas de recursos humanos nos serviços de saúde. Saúde Deb., (28): 66-71, 1990.

9. SPINK, M.J.P. A dimensão organizacional das politicas públicas. Cad. FUNDAP, 7(13): 27-33, 1987. 